\title{
A PROPÓSITO DA CLASSIFICAÇÃO BRASILEIRA UNIFORME DE OCUPAÇÕES
}

\author{
Taka Oguisso * \\ Maria Jcsé Schmidt*
}

PuBEn/01

OGUISso, T. e SCHMIDT, M.J. - A Propósito da Classificaçāo Brasileira Uniforme de Ocupaçōes. Rev. Bras, Enf.; DF, 29 : 6-23, 1976.

\section{INTRODUÇAO}

Se "estudar os assuntos que interessem à profissão colaborando com as autoridades na solução de problemas a ela reiacionados" constitui um dos objetivos estatutários da Associação Brasileira de Enfermagem - (ABEn), devemos nós, como enfermeiras, participar conscientemente desse empreendimento de envergadura, qual seja, a Classificação Brasileira Uniforme de Ocupaçōes.

Foi uma das razōes que motivou a ABEn - Seção de São Paulo e as autoras do presente trabalho, a colaborar diretamente na elaboração das descrições de ocupaçōes da enfermagem e, mais tarde, nas relacionadas com o setor da saúde. Realmente, esta ampliação progressiva dos parâmetros do exercício profissional está levando o enfermeiro a assumir novos compromissos com a sociedade, numa evidente demonstração da maturidade que a profissão já atingiu.

Para nós, enfermeiras, a oportunidade de colaborar neste empreendimento constituiu-se num verdadeiro privilégio pela riqueza de experiências novas, conhecimentos e relacionamentos obtidos no decorrer das reuniōes com Dr. Alfonso Camacho Pardo, Perito da Organização Internacional do Trabalho (OIT) e Assessor do Grupo-Tarefa da Classificação Brasileira de Ocupaçōes, as entrevistas e discussōes com uma gama imensa de profissionais da saúde, tais como: farmacêuticos, nutricionistas, médicos, veterinários, fisioterapeutas, terapeutas ocupacionais, cirurgiōes dentistas, ortopedistas, fonoaudiólogos e muitos outros.

Com a apresentação deste trabalho, as autoras se propōem atingir os seguintes objetivos:

a) contribuir para a conscientização profissional da necessidade do estudo científico da profissão, no sentido de avaliar sua importância relativa no mundo do trabalho, em função da importância das atribuiçōes determinadas e desenvolvidas e não apenas com títulos e diplomas como base para comprovação da eficiência;

b) apresentar os resultados de um trabalho prático realizado, que servirá de

* Enfermeiras do INPS - Såo Paulo. 
OGUIsso, T. e SCFMIDT, M.J. - A Propósito da Classificação Brasileira Uniforme de Ocupações. Rev. Bras. En?.; DF, 29 : 6-23, 1976.

base para verificação nacional e de instrumento de apreciação da importância das análises permanentes, como demonstrativo da magnitude deste tipo de estudo que será amplamente justificado pela complexidade própria da profissão;

c) oferecer oportunidade de discussão sobre o desenvolvimento social e econômico da profissão e sobre a nossa responsabilidade como profissionais engajados na estrutura social de hoje, participando dessa evolução tecnológica;

d) oferecer subsídios para a implantação e o desenvolvimento progressivo de programas e projetos necessários para a ava'iação científica da profissão, para a determinação de salários compatíveis com a natureza do trabalho (tanto em sua estimativa absoluta e real como proporcional às outras categorias ocupacionais), para a definição de tarefas no Ministério do Trabalho e, enfim, para solução de outros problemas que devam ser estudados.

Para maior facilidade na compreensão do problema e da sua importância na atualidade, foi incluído um pequeno histórico a respeito da Classificação de Ocupaçōes, em âmbito internacional e nacional.

Para a execução global desse empreєndimento, se prevê a participação de analistas, isto é, de pessoas que participam diretamente no planejamento, organização, normalização e desenvolvimento dos programas de promoção e pesquisas de análises nacionais de postos, além de grupos de apoio formados junto aos órgãos de classe; grupos técnicos de trabalho, formados por pessoal técnico das empresas, e grupos técnicos consultivos para análise dos estudos. documentos e informaçōes disponiveis nos Estados e nas áreas específicas do trabalho de grupo. Os instrumentos a serem utilizados serão: os formulários para verificação das descriçōes do trabalho, que constituem o laço de união entre 0 Grupo-Tarefa e os estabelecimentos se- lecionados; um processo combinado de tabulaçōes manuais e mecânicas para as análises quantitativas e qualitativas.

\section{RESENHA HISTÓRICA}

\subsection{No âmbito internacional}

A Classificação Internacional Uniforme de Ocupaçōes (CIUO) foi elaborada como resposta às necessidades de agrupar informaçōes acerca da Força de Trabalho, segundo critérios técnicos uniformes e universais, a fim de constituir-se em documento guia para as classificaçōes nacionais, conforme as realidades de cada país, conservando uma estrutura considerada indispensável para assegurar comparaçōes internacionais.

Nesse sentido, os Países Membros manifestaram à OIT sua preocupação ante as dificuldades crescentes de estudar os problemas relativos à mão-de-obra e à impossibilidade total de uma análise comparativa das informaçōes e recomendaram cooperar no assunto para buscar soluçōes adequadas. $O$ processo de trabalho, gerado em decorrência dessas circunstâncias, para a elaboração da CIUO 1958, teve a duração de nove anos e a sua revisão, a cargo de um grupo especial, constituído por técnicos internacionais, exigiu quatro anos de trabalho permanente.

\subsection{No âmbito nacional}

A execução dos estudos relacionados com os recursos humanos do país e sua incorporação na planificação geral do desenvolvimento, exigem a normalização na classificação da força de trabalho por categorias ocupacionais, tendo prioridade nos censos de população, nas pesquisas de tipo específico e nas avaliaçōes permanentes de mercado de trabalho, sendo responsabilidade do Departamento Nacional de Mão-de-Obra (DNMO) do Ministério do Trabalho a Identificação 
OGUIsso, T. e SCHMIDT, M.J. - A Propósito da Classificaçāo Brasileira Uniforme de Ocupações. Rev. Bras. En?.; DF, $29: 6-23,1976$.

Profissional e a elaboração da classificação das profissões (Decreto 58.550/66).

Para desenvolver suas funçōes específicas, muitos dos organismos especializados do país elaboraram trabalho nesse sentido. No entanto, os documentos elaborados, pela sua própria índole, foram de escassa utilidade global, devido, tanto às limitações dos campos abrangidos ou à ausência de definições das categorias consideradas, como à inobservância de técnicas comuns de elaboração.

O DNMO, preocupado com o problema, publicou em 1971 o que intitulou "Cadastro de Ocupações", obtido de 103 informes de empresas. Esse documento tem em vista a antiga estrutura da CIUO e contém 522 ocupaçōes identificadas de maneira geral.

A partir de 1971, iniciou-se o Projeto OIT/BRA/68/006, assinado entre o Governo do Brasil e a Organização Internacional do Trabalho para planejar e elaborar a Classificação Uniforme de Ocupaçōes (CBUO), tenđo em vista, principalmente, o planejamento da mãode-obra e da formação profissional. Durante a execução desse Projeto, o título utilizado foi Classificação Brasileira de Ocupações (CBO), tendo em vista que nas carteiras de trabalho, previu-se um lugar para o código da ocupação com esta sigla. Entretanto, está sendo recomendada a substituição desta sigla, por já ter sido ela adotada para designar a Coleção Básica Ocupacional (CBO), estando assim comprometida a terminologia na América Latina. Além disso, a adoção do título Classificação Brasileira Uniforme de Ocupaçōes (CBUO) corresponderia mais exatamente ao espírito do documento de base utilizado neste trabalho. Por esta razão, daqui por diante, será utilizada a sigla corrente, isto é, CBUO, a não ser quando se tratar do Grupo-Tarefa, que foi criado sob o título GT/CBO.

Com início do mencionado Projeto, efetivaram-se os estudos de base, indispen- sáveis para definir as necessidades do país no campo específico de classificação de ocupações, para verificar as possibilidades de aproveitamento dos documentos existentes e para definir uma estratégia de conjunto para desenvolver um plano de ação encaminhado à elaboração da classificação brasileira, considerando as exigências e realidades nacionais.

Posteriormente, o Projeto OIT/BRA/006 foi incorporado ao Projeto de Planejamento de Recursos Humanos que atualmente desenvolve o Governo Brasileiro, em cooperação com o Programa das Nações Unidas para o Desenvolvimento (PNUD). Esse projeto, conhecido como Projeto BRA/70/550, contém quatro áreas integrais que serão efetivadas pelas agências do Governo para fortalecer a infra-estrutura necessária ao desenvolvimento do planejamento dos recursos humanos brasileiros.

As áreas do projeto correspondem às relacionadas com os sistemas de informação, estudos e pesquisas, planejamento e acompanhamento e treinamento de pessoal. A elaboração da CBUO situa-se na área de informação por ser o instrumento indispensável à agrupação das informaçōes de mão-de-obra, segundo o trabalho executado e os requisitos exigidos aos trabalhadores.

\section{METODOLOGIA}

O estudo do método para a elaboração da CBUO compreende a definição de meios e normas técnicas para efetivar o registro, a análise e o exame crítico sistemático dos modos operativos, objetivando a implantação do Sistema Nacional Uniforme de Ocupações, mediante o desenvolvimento e aplicação de métodos mais simples e eficazes nos diferentes programas e projetos específicos do plano, ou seja, objetivando a optimização das técnicas usuais e propostas para este tipo de pesquisa. 
OGUISSO, T. e SCHMDT, M.J. - A Propósitu da Classificaçāo Brasileira Uniforme de Ocupaçōes. Rev. Bras. Enf.; DF, $29: 6-23,1976$.

Conseqüentemente definiu-se uma amostra nacional de estabelecimentos, tomando como unidades primárias os Estados e Territórios Nacionais, sendo definidos centros chaves de produção e emprego para a seleção de unidades representativas de estudo, dentro do marco da amostra global. Dessa forma, pretendeu-se satisfazer as exigências nacionais, no sentido de obter uma boa representação das ocupações regionais e das categorias ocupacionais do País.

Com base na amostra, considera-se que todas as categorias ocupacionais, dentro de suas principais modalidades, estariam representadas. No entanto, o número de estabelecimentos foi reduzido na seleção regional, passando a cifra original a ser um elemento de guia para assegurar a representação indispensável aos fins da pesquisa.

\section{ESTUDO DA ESTRUTURA DA CLASSIFICAÇAO BRASILEIRA UNIFORME DE OCUPAÇŐES}

A elaboração da estrutura da CBUO consiste na ordenação dos elementos de classificação da força de trabalho, tendo em vista a similitude na execução das tarefas principais que se realizam e indicando as inter-relações existentes por meio do sistema de Classificação Decimal

\subsection{Ordenação de seus elementos}

Os elementos da classificação estão constituidos por Grandes Grupos, Subgrupos, Grupos Primários ou de Base e Ocupaçōes ou Categorias Ocupacionais, determinando assim, quatro graus de desagregação bem definidos, sendo que os Grandes Grupos constituem a divisão mais agregada e as categorias ocupacionais a mais desagregada.

Como base para o trabalho, adotou-se a Classificação Internacional Uniforme de Ocupações revisada em 1968 (edição castelhana). A partir da estrutura do documento em referência, dever-se-ão definir os Subgrupos e Grupos Primários da Classificação Nacional.

Para efeito da estrutura da CBUO foram adotados os oito Grandes Grupos da CIUO. Estes Grandes Grupos correspondem a amplas áreas ocupacionais, que nem sempre demarcam as modalidades especificas do trabalho.

Em principio, foram adotados como base de estudo para a estrutura da CBUO, os Subgrupos contidos na CIUO. Considerando que os Subgrupos estabelecem divisões menos dispersas que os Grandes Grupos, é indispensável estudar a adaptação destes elementos às modalidades nacionais, tendo em vista as necessidades peculiares dos usuários naturais da CBUO, fundamentalmente nos campos de estatística, colocaçōes e p’anejamento da mão-de-obra, como parte do plano geral de desenvolvimento.

Pelo mesmo significado e utilidade dos Subgrupos, o indicador principai deve ser a fisionomia da força de trabalho, tendo em vista as agrupações feitas nos censos de população e nas pesquisas econômicas e sociais do país. Não obstante, as alterações dos Subgrupos da CIUO terão que ter grande justificativa, procurando manter sempre os elementos de classificação necessários nas comparações de tipo internacional.

O termo Grupo Primário está empregado no sentido de fundamental ou básico, tendo em vista sua utilidade prática no processamento das informaçōes.

Em geral, as considerações feitas para os Subgrupos são, em grande medida, aplicáveis aos grupos primários. porém sendo também utilizados indicadores complementares do tipo qualitativo, que não têm o mesmo peso no caso dos Subgrupos.

Certamente, os grupos primários constituem um dos elementos de classificação mais importantes para estudo das informações acerca da mão-de-obra. Seu objetivo principal é reunir ocupaçōes afins, em função do trabalho que se realiza para formar "famílias de ocupaçōes" que 
OGUISso, T. e SCHMIDT, M.J. - A Propósito da Classificaçāo Brasileira Uniforme de Ocupaçōes. Rev. Bras. Enf.; DF, 29 : 6-23, 1976.

apresentem analogias nas tarefas principais e, sendo possível nos graus de formação, requisitos profissionais e responsabilidades exigidas para sua execução.

Sendo os grupos primários mais homogêneos que os subgrupos, além do número de trabalhadores das ocupaçōes que estes cobririam, dever-se-iam fazer intervir outros critérios e indicadores particulares e adequados, para distinguir as inter-relações das ocupações que integrariam o grupo primário em estudo e sua importância para a planificação dos recursos humanos nacionais. Tais critérios e indicadores deveriam ser definidos previamente, tendo em vista os grupos em estudo. Assim, por exemplo, na CIUO, consideroul-se como critério de c'assificação para o pessoal docente, os níveis de ensino e não as matérias lecionadas.

Não obstante, o critério fundamental é o trabalho que se faz.

$\mathrm{Na}$ prática, podem-se observar, com bastante freqüência, certas tendências para relacionar a mão-de-obra com atividades econômicas ou, ainda, com produtos que fabricam ou vendem, ou com os serviços que prestam, distorcendo, assim, os critérios de classificação de ocupaçōes. Em determinados casos, os grupos primários podem corresponder a certas agrupações econômicas, devido à estreita correlação existente entre trabalho e produção, como é o caso da Agricultura e Indústria Extrativa.

4.2. Unidade de estudo e seus componentes

A ocupação ou categoria ocupacional é a unidade de estudo ou de classificação. Reúne postos de trabalho semelhantes, quanto à execução das tarefas principais, pois os niveis de conhecimentos, habilidades e atitudes exigidos aos trabalhadores são iguais ou similares.

A unidade de estudo contém uma série de elementos técnicos que permitem sua desagregação ou sua agregação, segundo objetivos em casos específicos. possível desagregar a ocupação dividindo seus elementos nos conceitos de: cargo, posto de trabalho, tarefa principal, operação, ato e micro-ato. t possível agregar a ocupação, unindo as categorias ocupacionais em grupos primários ou famílias de ocupações, subgrupos e grandes grupos. Na prática, o anterior pode-se resumir nos seguintes termos:

micro-ato - expressão mínima de um processo produtivo;

ato - conjunto de expressões sucessivas; operação - conjunto de atos semelhantes;

tarefa principal - conjunto de operações semelhantes que apresentam uma estrutura definida;

posto de trabalho - conjunto de tarefas e obrigações designadas a um trabalhador, para serem cumpridas em uma unidade de trabalho criada por decisão da empresa;

cargo - conjunto de postos de trabalho semelhantes;

ocupação - conjunto de cargos semelhantes.

\section{METODOLOGIA APLICADA PARA O SETOR SAÚDE}

\subsection{Objetivos:}

a) Identificar as tarefas principais que são realizadas em cada categoria ocupacional;

b) promover e estimular a colaboração de órgãos de classes na definição das atribuições de seu campo;

c) efetivar a participação de representantes de cada categoria profissional na descrição das respectivas ocupações.

5.2. Período coberto e participação efetivada

Embora as descrições de tarefas dos profissionais da saúde não estejam ainda concluídas, a coleta de dados para a elaboração das descrições foi realizada na Região do Grande São Paulo, no período 
de agosto de 1973 a maio de 1974, com entrevistas e reuniōes em hospitais. ambulatórios, centros de saúde, laboratórios, bancos de sangue, centros de reabilitação, serviços de radioterapia, farmácias, sede de associações de classe, conselhos regionais, Coordenadoria da Saúde da Comunidade da Secretaria da Saúde do Estado, Coordenação de Assistência Médica do Instituto Nacional de Previdência Social (INPS), Serviço de Fiscalização do Exercício Profissional de Medicina, Odontologia e Farmácia e até em residências dos profissionais.

\section{3. Sistema de co!eta}

$O$ instrumento básico utilizado na fase de coleta de dados para elaboração das descrições foi a entrevista. Optou-se pela entrevista direta, considerando-se as vantagens de:

a) ser mais eficaz a coleta de dados;

b) possibilitar entendimento e técnica uniforme;

c) permitir maior precisão e fidedignidade nas respostas.

Como complementação e avaliação do método, foram utilizadas reuniões com três a quatro profissionais da mesma categoria na execução normal da tarefa em análise.

5.4. Prccedimento e técnica da entrevista

Para as entrevistas, procura-se s` mpre o profissional militante no próprio camno de trabalho, por indicacão de diretores de serviço, coordenadores de área, membros de diretoria de órgãos de classe ou simplesmente colegas de profissão. Também a nossa vivência e relacionamento profissional, como integrantes da anuine de saúde, foram abrovoitados para facilitar o estabelecimento do "rapport" na obtenção das informações necessárias. Os órgãos oficiais de assistência à saúce no âmbito federal e estadual contribuíram ativamente, não só indicando profissionais e especialistas que vinham se destacando no desenvolvimento de trabalhos mas, também, convocando-os para reuniões ou entrevistas, facilitando sobre- maneira o trabalho de elaboração de algumas descrições. $O$ órgão de fiscalização do exercício profissional também muito auxiliou. orientando a respeito das ocupações, profissões e entidades de sua jurisdição e indicando estabelecimentos (farmácias, laboratórios) e profissionais que poderiam colaborar no trabalho.

$\mathrm{Na}$ entrevista, pedia-se aos profissionais que descrevessem dentro de possível sequência lógica as coisas que executavam em seu trabalho. A medida que o entrevistado relatava, perguntava-se-lhe como as executavam e com que finalidade. Freqüentemente, havia confusão entre competências do serviço ou órgão com as tarefas próprias do cargo, ou então as tarefas do profissional em cargo de chefia ou comando, com as dele, como profissional ou especialista, propriamente dito.

Nos casos em que o entrevistado não conseguia explicar em palavras a maneira ou como executava determinada tarefa, solicitava-se uma demonstração, utilizando o próprio material usual e no local mesmo da execução normal da tarefa.

$\mathrm{Na}$ elaboração descritiva de uma ocupação nova desconhecida das analistas, já se preparava durante a primeira entrevista uma descrição preliminar e deixava-se uma cópia manuscrita para o profissional consultar outros colegas dentro de um prazo variável de 10 a 15 dias. Na data prevista, as analistas retornavam ao local com a descrição já burilada e colocada na forma e padrões técnicos estabelecidos, para confrontação com o resultado obtido pelos profissionais. Nesta obortunidade, geralmente, era promovida vma reunião entre as analistas e os profissionais da categoria, para discussão dos termos e tarefas e escolha da descrição que melhor retratasse a realidade.

Tratando-se de uma ocupação ou especialidade conhecida, as próprias analistas, em geral, com base em suas experiências, antes de marcar a entrevista, já elaboravam uma descrição básica para servir de referência e discussão. Com esta descrição era possível discutir-se com di- 
OGUIsso, T. e SCFMmT, M.J. - A Propósito da Classificaçāo Brasileira Uniforme de Ocupaçōes. Rev. Bras. Enf.; DF, $29: 6-23,1976$.

versos profissionais do mesmo campo, isoladamente ou em grupo, corrigindo-se sempre, sobre a descrição revisada pelo profissional anterior. Havendo desacordc de algumas tarefas, procurava-se entrosar os profissionais discordantes através de uma reunião para decisão, ou fornecendo a cada um o parecer do outro, com as justificativas. Estas discordâncias ocorreram poucas vezes, e geralmente eram oriundas do idealismo de um profissional, ao mesmo tempo em função docente, frente ao realismo do profissional de campo.

No decorrer das entrevistas, ou em visitas às diversas instituições, foram sendo descobertas ocupações e especialidades novas, alargando-se ainda mais $c$ campo das profissões de saúde. Já no final, representantes de ocupações, através de suas associações, procuravam a Delegacia Regional do Trabalho, pedindo para serem entrevistados e incluídos na Classificação de Ocupações. Em algumas subespecialidades, sobretudo as mais recentes, notou-se grande interesse em figurar na CBUO, procurando esses profissionais demonstrar e provar a área de atuação exclusiva.

5.5. Fases para elaboração da descrição de base

Após as entrevistas com quatro a cinco ou mais profissionais da categoria, fazia-se uma revisão geral da descrição. Algumas instituições de ensino foram procuradas, ao final, para correção de impropriedades terminológicas, quando necessário. No início, estas descrições eram ainda discutidas no Grupo-Tarefa da CBO, juntamente como o Perito da OIT, que dava orientações e diretrizes técnicas para que fosse mantida a uniformidade e padrões estabelecidos.

Essas descrições dos profisisonais da saúde, foram ainda submetidas ao exame crítico de um grupo de cerca de sessenta entidades que mais diretamente cooperaram na elaboração de listas de ocupações e descrições de tarefas. Com uma antecedência de cinco a dez dias, foram distribuídos a essas entidades, juntamente com ofício do Delegado Regional do Trabalho, volumes mimeografados de descrições do pessoal da saúde. convidando-as a examinar o conteúdo e participar de reunião, levando sugestões e críticas. Entre as entidades convidadas, estavam a Secretaria de Estado da Saúde, o INPS, Conselhos Regionais, Associações de Classe, Sindicatos, Serviço de Fiscalização do Exercício Profissional e representantes de hospitais e outros serviços de saúde. Nesta reunião, realizada a 4 de abril de 1974, após uma exposição sobre as finalidades do Projeto de Planejamento de Recursos Humanos feita pelo seu Diretor, Dr. Samuel Levy, e sobre o histórico, objetivos, métodos de desenvolvimento dos trabalhos para a Classificação de Ocupações, feita pelo Perito da OIT, foram discutidas algumas descrições de base.

Resta a verificação em âmbito nacional das descrições de base, que será feita pelo DNMO por intermédio das Delegacias Regionais de Trabalho. Esta verificação será realizada, enviando-se o formulário, contendo as descrições de base aos respectivos postos de trabalho. profissionais ou especialistas sediados na jurisdição da Delegacia. Esses profissionais farão uma análise crítica dizende adiante de cada tarefa, se ela:

a) é exata - quando a tarefa é feita da mesma maneira e com os mesmos objetivos gerais;

b) é diferente - quando executada de outra maneira ou com outros meios, porém buscando os mesmos objetivos;

c) pode ser assim - quando é executada eventualmente, ou seja, sem caráter permanente ou regular;

d) faz parte de outra ocupação quando se constitui em tarefa principal de ocupação diferente;

e) é outra ocupação - quando seu conteúdo corresponde às obrigações globais de outra ocupação;

1) não existe - quando não é executada no estabelecimento. 
OGUIsso, T. e SCFMmT, M.J. - A Propósito da Classificaçāo Brasileira Uniforme de Ocupaçōes. Rev. Bras. Enf.; DF, $29: 6-23,1976$.

As palavras ou frases que os profissionais, em cada localidade, entenderem estar erradas, serão riscadas e escritas as certas nas entrelinhas.

Somente após o retorno dos formulários ao DNMO é que os analistas poderão elaborar sinteses das definições nacionnais que serão codificadas conforme a estrutura da CBUO.

\section{O ENFERMEIRO NA CLASSIFICAÇAOO BRASILEIRA UNIFORME DE OCUPAÇOEES}

O Enfermeiro na Classificação Internacional Uniforme de Ocupações está classificado no Grande Grupo 0/1 de Profissionais, Técnicos e Trabalhadores Assemelhados, Subgrupo 0-6/0-7 de Médicos, Odontólogos, Veterinários e Trabalhadores Assemelhados, sob o Grupo Primário 0-71 - Enfermeiros.

Como integrantes desse Grupo Primário, e em razão da condição em que nб̆s, enfermeiras, passamos a colaborar com - Grupo-Tarefa da CBO, evidentemente, foi a primeira categoria a ser descrita. Preliminarmente, fol solicitada ao Perito da OIT, a alteração do título atual do Subgrupo 0-6/0-7 para Profissionais da Saúde, em substituição a "Médicos, Odontólogos, Veterinários e Trabalhadores Assemelhados", visto que ele não expressa toda a gama de profissionais que o integram, ao passo que "Profissionais da Saúde", todas as categorias ocupacionais incluídas, o são.

Antes de procedermos à elaboração propriamente dita das descriçōes, foram l1das e estudadas todas as instruçōes concernentes ao trabalho.

Constatamos que a elaboração de descriçōes de base das tarefas principais e opcionais é feita observando-se o método da divisão do conteúdo global do trabalho em blocos ou tarefas principais, entendidas como as obrigaçōes que exigem do trabalhador a maior dedicação em termos de tempo de trabalho ou de utili- zação de conhecimentos, destrezas e habilidades ou, ainda, a aplicação de esforço físico do indivíduo.

No processo de elaboração das descriçōes procurou-se observar os seguintes passos:

a) definir resumidamente o conteúdo giobal da ocupação, tendo em vista seus objetivos específicos;

b) dividir este conteúdo global em blocos ou tarefas principais, ordenandoos segundo sequiência lógica, determinada pelo próprio processo produtivo;

c) descrever cada uma das tarefas principais de maneira reflexiva, buscando explicar o que se faz, como se faz e para que se faz, indicando equipamentos, ferramentas e materiais utilizados, quando escapam ao senso comum;

d) revisar a descrição de cada uma das tarefas, a fim de assegurar sua clareza, exatidão e objetividade;

e) assegurar a correta ordenação das tarefas, segundo seqüência inerente à realização do trabalho.

Para maior facilidade na identificação das tarefas principais, foram utilizados alguns dos seguintes guias ou indicadores:

a) a tarefa principal tem importância absoluta, no sentido em que é indispensável para o cumprimento dos objetivos da ocupação;

b) cada tarefa principal tem uma f1nalidade que exige do trabalhador a aplicação de conhecimentos, destrezas e habilidades significativas ou de um esforço físico importante, assim como a utillzação de boa parte de seu tempo útil de trabalho para sua execução;

c) a tarefa principal se realiza segundo metodologia própria e observando diretrizes ou normas técnicas previamente estabelecidas; e,

d) na tarefa principal concorrem uma série de aspectos quantitativos e qualitativos de interesse para sua execução, tais como: velocidade, qualidade, frcqüência, produtividade, etc. 
OGUISSO, T. e SCHMIDT, M.J. - A Propósito da Classificação Brasileira Uniforme de Ocupaçōes. Rev. Bras. Enf.; DF, 29 : 6-23, 1976.

Na metodologia para coleta dos dados, valemo-nos, também, de nossa vivência profissional de campo e consulta a regulamentos, manuais de serviço, definição de atribuiçōes e outros documentos.

Podemos afirmar que muito há, ainda, a explorar no campo do estudo da profissão, especialmente se partirmos para a análise ocupacional e profissiograma, que serão objetos de estudo futuro.

Ccmo etapa inicial, apresentamos, em anexo, as descriçōes de base de: Enfermeiro, em geral, Enfermeiro de Saúde Pública, Enfermeiro de Higiene do Trabalho, Enfermeira Obstétrica ou Obstetriz, Auditor de Enfermagem, Enfermeiro Puericultor e Pediátrico, Enfermeiro Psiquiátrico, Enfermeiro de Centro Cirúrgico, Enfermeiro de Terapia Intensiva, Professor de Curso Superior de Enfermagem e Obstetrícia e Professor de Enfermagem de $1 .^{\circ}$ e $2 .^{\circ}$ graus.

As especialidades descritas serão codificadas, se prevalecerem, após a verificação nacional e integrarão a Classificação Brasileira Uniforme de Ocupaçōes.

\section{CONCLUSŌES E RECOMENDAÇŐES}

O presente trabalho, focalizando uma das etapas básicas para elaboração da Classificação Brasileira Uniforme de Ocupaçōes, pode apresentar à guisa de conclusão que:

a) há, ainda, de uma maneira geral, desconhecimento e relativo desinteresse de algumas categorias profissionais, da área de saúde, pela sistematização de uma análise descritiva correta, especialmente entre aquelas que já gozam de "status" social;

b) por outro lado, sua importância foi reconhecida entre aquelas categorias ocupacionais de criação mais recente e que ainda lutam por uma regulamentação ou reconhecimento social.

Considerando a relevância do assuntn e o interesse para a profissão, RECOMENDAMOS: a) que as Seçōes da ABEn promovam ampla divulgação das descriçōes de base das tarefas do Enfermeiro a fim de favorecer a colaboração dos profissionais enfermeiros quando da verificação nacional a ser feita pelo DNMO e pelas Delegacias Regionais do Trabalho;

b) aos enfermeiros em geral, que se preparem pelo estudo e pesquisa para a implantação de um sistema permanente para análise e atualização metódica da ocupação, tendo em vista a evolução do mercado de trabalho e das estruturas organizacionais das empresas e instituiçōes de saúde.

\section{REFERENCIAS BIBLIOGRAFICAS}

1. CAMACHO PARDO, A. - Resumo do curso ministrado ao pessoal do Grupo-Tarefa encarregado de elaborar a Classificação Brasileira de Ocupaçōes, Rio, MTPS, DNMO, 1972.

8.2. CAMACHO PARDO, A. - Algumas informaçōes acerca dos programas em execuçảo para elaborar a Classificação Brasileira Uniforme de Ocupaçōes, Rio, 'MTPS, DNMO; 1973

8.3. GOODE, W.J. \& HATT, P.K. - Métodos em Pesquisa Social, 2. ${ }^{\mathrm{s}}$ ed., São Paulo, EJ. Nacional, 1968.

8.4. MINISTERIO DA SAUUDE - Padrō ’s de atribuiçōes do pessoal de enfermagem, Instituto Presidente Castello Branco; Depto. Recursos Humanos para a Saúde, 15.72, mimeografado.

8.5. FERRARINI, C. \& al - Manual da Subdivisão de Enfermagem do Hospital das Clínicas da Faculdade de Medicina da Universidade de São Paulo, SP.

8.6. MT/DNMO - Instrução GT/CBO n. 6 - Instrução para utilizaçño do formulário de verificação de tarefas, 26-2-73.

8.7. MT/DNMO - Instrução GT/CBO n. 7 - Instrução para elaboração de descrição de tarefas, 25-2-73.

\section{DESCRIÇAO DAS TAREFAS PRINCIPAIS}

ENFERMEIRO, EM GERAL (E-0297)

Exerce atividades de planejamento, 
OGUISSO, T. e SCFMMT, M.J. - A Propósito da Classificação Brasileira Uniforme de Ocupaçōes. Rev. Bras. Enf.; DF, $29: 6-23,1976$.

organização, programação, coordenação, supervisão, orientação e execução de serviços de enfermagem por meio de estudos, avaliaçōes, levantamentos, pesquisas. prestação de assistência, desenvolvimento de programas educativos e outros, visando a proteção, a recuperação e a reabilitação da saúde individual ou coletiva:

1. identifica as necessidades de enfermagem por meio de entrevistas, participação em reuniōes e observação sistematizada com o propósito de promover, preservar, recuperar e reabilitar a saúde e elabora o plano escrito de assistência a ser prestada pela equipe de enfermagem nas 24 horas;

2. presta assistência direta de enfermagem a pacientes em estado grave por meio da administração de sangue e plas$\mathrm{ma}$, do controle da pressão venosa, monitorização e de respiradores artificiais, da prestação de cuidados de conforto, movimentação ativa e passiva e de higiene pessoal, da aplicação de diálise peritonial, gasoterapia, cateterismos, instilacōes, lavagens de estômago, vesical e outros tratamentos a fim de proporcionar o maior grau possível de bem-estar físico, mental e social;

3. executa tarefes complementares ao tratamento médico especializado em casos de cateterismo cardíaco, transplante de órgãos, hemodiálise e outros, preparando o paciente, o material e o ambiente, para maior eficiência na realização dos exames e tratamentos;

4. efetua testes de sensibilidade por meio da aplicação de substâncias alergônicas e leitura das reaçōes para subsídios diagnósticos;

5. presta socorro em situaçōes de emergência, fazendo curativos e imobilizaçōes especiais e administrando medicamentos e tratamentos a fim de atenuar as conseqüências;

6. promove a adaptação do paciente ao ambiente hospitalar e aos métodos terapêuticos que lhe são aplicados, por meio de entrevistas de admissão, de visitas diárias ao mesmo e orientaçōes, com o objetivo de reduzir sua sensação de insegurança e sofrimento e obter sua colaboração ao tratamento;

7. presta cuidados "post-mortem'" por meio de enfaixamentos e tamponamentos para evitar eliminação de secreçōes e melhorar a aparência e assiste e orienta familiares dando apoio e encaminhando-os para a formalização de atestados e certidōes para sepultamento;

8. elabora, executa ou supervisiona e avalia planos de assistência a pacientes geriátricos por meio da observação sistematizada, entrevista e cuidados diretos com o propósito de auxiliar no seu processo de adaptação e reabilitação;

9. coordena e supervisiona o pessoal da equipe de enfermagem por meio de observação, entrevistas, reuniōes de orientação e avaliação, a fim de manter os padrōes desejáveis de assistência de enfermagem;

10. faz estudos e previsão de pessoal e material necessários para as 24 horas de atividades, por meio da elaboração de escalas de serviço, de atribuiçōes diárias e da especificação e controle de equipamentos, materiais permanentes e de consumo para assegurar o desempenho adequado da assistência de enfermagem;

11. requisita e controla entorpecentes e psicotrópicos, mediante a apresentação da receita médica devidamente preenchida e dando saída no "livro de controle", a fim de evitar desvio dos mesmos e atender às disposiçōes legais;

12. avalia a assistência de enfermagem, por meio da análise e interpretação dos dados estatísticos e registros das atividades para estudar melhor 0 aproveitamento do pessoal;

13. planeja, organiza e administra serviços ou unidades de enfermagem em instituiçōes de saúde, desenvolvendo atividades técnico-administrativas na elaboração de normas, instruçōes, roteiros 
OGUIsso, T. e SCFMmT, M.J. - A Propósito da Classificaçāo Brasileira Uniforme de Ocupaçōes. Rev. Bras. Ent.; DF, 29 : 6-23, 1976.

e rotinas especificas, a fim de padronizar procedimentos, racionalizar os trabalhos e servir de apoio para atividades fins;

14. participa de grupos de trabalho, comissōes e equipes multiprofissionais emitindo pareceres, executando trabalhos especificos ou assessorando em assuntos de enfermagem para levantamento e identificação de problemas, estudo de soluções, elaboração de planos, programas e projetos e desenvolvimento de pesquisas;

15. promove o conforto e a segurança do ambiente de trabalho por meio da implantação de normas e medidas de proteção a fim de evitar acidentes;

16. registra as observaçōes, tratamentos executados e ocorrências verificadas com relação ao paciente, anotando no prontuário hospitalar, ficha de ambulatório, relatório de enfermagem da unidade ou relatório geral, para documentar a evolução da doença, controle de saúde e orlentar a terapêutica e a pesquisa;

17. planeja, programa e desenvolve 0 treinamento sistemático em serviço para 0 pessoal da equipe de enfermagem por meio da avaliação das necessidades e dos níveis de assistência prestada, visando a indução de pessoal recém-admitido, o aprimoramento ou introdução de novas técnicas de enfermagem e a melhoria dos padrões de assistência.

\section{ENEFRMEIRO DE SAŨDE PUBLICA}

\section{Código (0-71.30)}

Executa atividades similares às do enfermelro, em geral (E-0297), e participa no planejamento, execução e avaliação dos programas de saúde através da atuaęäo técnico-administrativa nos serviços de saúde pública, da prestação de assistêncla global de enfermagem a individuos, famillis e outros grupos sociais dentro da comunidade, do desenvolvimento de programas educativos para o pessoal de enfermagem e para a comuni- dade e das pesquisas em enfermagem e em saúde pública, para promoção, proteção e recuperação da saúde de uma coletividade:

1. coleta e analisa, juntamente com a equipe de saúde, dados sócio-sanitários da comunidade a ser atendida pelos programas específicos de saúde, por meio da consulta e compllação de dados registrados em instituiçōes da comunidade (cartórios, serviços de saúde e outras que prestam assistência sócio-sanitária), inquéritos junto à população ou às instituiçōes, entrevistas e observaçōes, para obtenção de dados não registrados, com o propósito de fazer diagnósticos e prognósticos da situação de saúde da comunidade;

2. elabora, juntamente com a equipe de saúde, normas técnicas e administrativas para os serviços, consultando documentos de outras entidades, para programar as ações de saúde em bases científicas;

3. estabelece, juntamente com a equipe de saúde, os programas para uma coletividade, elaborando um plano escrito com base nas prioridades, tempo, produção e custo em função do atendimento das necessidades de saúde da população, dentro dos recursos disponíveis;

4. planeja, organiza, dirige, coordena, controla e avalia os serviços de enfermagem de saúde pública por melo de estudos, análises, avaliaçōes, orientaçōes e supervisão para manutenção de um padrão elevado de assistência de enfermagem;

5. planeja, e desenvolve atividades específicas de assistência a indivíduos, famílias e outros grupos da comunidade, por meio de consultas de enfermagem, visitas domiciliares, testes de imunidade, vacinaçōes e investigaçōes que permitam promover e proteger a saúde de grupos prioritários e aumentar a cobertura dos programas;

6. supervisiona a execução dos cuidados de enfermagem mais simples por melo da observação e orientação das técnicas 
OGUIsso, T. e SCHMIDT, M.J. - A Propósito da Classificaçāo Brasileira Uniforme de Ocupaçōes. Rev. Bras. Ene; DF, 29 : 6-23, 1976.

planejadas e ensinadas pelo enfermeiro e delegadas ao pessoal auxiliar de enfermagem, a um membro da família ou a outras pessoas da comunidade para maior eficiência do tratamento e promoção da saúde;

7. planeja, executa e avalia programas educativos para grupos da comunidade atendendo as prioridades, ministrando cursos e palestras, coordenando reuniōes e aplicando testes de avaliação de conhecimentos para motivar o desenvolvimento de atitudes e hábitos sadios;

8. participa, juntamente com outros membros da equipe dä saúde pública, na organização de grupos da comunidade através do reconhecimento da situação sócio-sanitária, do enfoque dos aspectos prioritários, visando dinamizar a população para cooperar na solução de seus próprios problemas;

9. participa nos programas de formação e informação para profissionais na área da saúde pública, fazendo palestras, demonstraçōes e revisões das técnicas específicas, supervisão e avaliação do rendimento do educando, no campo de estágio a fim de proporcionar-lhe a observação, a aprendizagem ou a experiência nos aspectos de enfermagem de saúde pública;

10. realiza pesquisas em enfermagem e participa em pesquisas de outras áreas do campo da saúde, por meio de estudos, levantamentos, análises e outros, visando melhorar os padrões de saúde individual e coletiva;

11. assessora em assuntos de enfermagem as autoridades sanitárias, grupos da comunidade e equipe de enfermagem, emitindo pareceres de sua especialidade ou orientando a fim de oferecer subsídios para fundamentação de arrazoados, informes, documentos e despachos.

\section{ENFERMEIRO DE HIGIENE DO TRABALHO}

Executa as atividades similares às do enfermeiro, em geral (E-0297) e parti- cipa de serviço de Higiene, Medicina e Segurança do Trabalho por melo de estudos, levantamentos, prestação de assistência, desenvolvimento de programas educativos com a finalidade de preservação da saúde e valorização do trabalhador pela promoção do maior grau possivel de bem-estar físico e social.

1. participa do planejamento, instalação e funcionamento do serviço de segurança, higiene e medicina do trabalho por meio de estudos e levantamentos para identificação das necessidades da empresa;

2. participa da elaboração e execução de planos e programas de proteção da saúde dos empregados, por meio de inquéritos sanitários, estudo das causas de absenteísmo, levantamento de doenças profissionais e lesões traumáticas, estudos epidemiológicos, coleta de dados estatísticos de morbidade e mortalidade de trabalhadores, investigando possíveis relações com as atividades funcionais visando a continuidade operacional e o aumento da produtividade;

3. participa da elaboração, execução e avaliação de programas de prevenção de acidentes e de doenças profissionais, ou não, por meio da análise da fadiga, de fatores de insalubridade, dos riscos e das condições de trabalho do menor e da mulher, visando a preservação da integridade física e mental do trabalhador;

4. presta os primeiros socorros no local de trabalho em caso de acidente ou doença, fazendo curativos ou imobilizações especiais e administrando medicamentos e tratamentos e providenciando o posterior atendimento médico adequado a fim de atenuar as conseqüências e proporcionar apoio e conforto ao paciente;

5. elabora e executa ou supervisiona e avalia a assistência de enfermagem aos trabalhadores, proporcionando-lhes atendimento ambulatorial, no local de trabalho, por meio de controle de sinais $\mathrm{Fl}$ tais, aplicação de medicamentos prescritos, curativos, inalações, testes para sub- 
OGUISSO, T. e SCHMIDT, M.J. - A Propósito uaa Classificaçāo Brasileira Uniforme de Ocupaçōes. Rev. Bras. Ene.; DF, 29 : 6-23, 1976.

sídios diagnósticos, colheita de material para exame laboratorial, vacinaçōes e outros tratamentos a fim de reduzir o absenteísmo;

6. organiza e administra o setor de enfermagem da empresa, prevendo pessoal e material necessários, treinando e supervisionando auxiliares de enfermagem do trabalho, atendentes e outros a fim de prover atendimento adequado das necessidades de saúde do trabalhador;

7. colabora com a Comissão Interna de Prevenção de Acidentes (CIPA) por meio do controle das ocorrências acidentárias, análise das causas e treinamento de trabalhadores, no que se relaciona com assuntos ligados à preservação e proteção da saúde com o propósito de reduzir a incidência de acidentes;

8. planeja e executa programas de educação sanitária divulgando conhecimentos, estimulando a aquisição de hábitos sadios, visando a prevenção de doenças profissionais e a melhoria das condiçōes de saúde do trabalhador;

9. mantém cadastros por meio de registro de dados estatísticos dos acidentes e doenças profissionais a fim de orientar a prevenção, calcular o custo e preparar informes para subsídios processuais nos pedidos de indenizaçōes ou outros.

\section{ENFERMEIRA OBSTETRICA OU OBSTETRIZ (Código 0-73.10)}

Executa tarefas similares às do enfermeiro em geral (E-0297), e presta assistência específica de enfermagem à mulher no ciclo grávido-puerperal e ao recém-nascido, por meio da observação e controle da gestante, da parturiente, da puérpera e dos cuidados imediatos ao recém-nascido, a fím de diminuir a morbidade e mortalidade materna e fetal:

1. planeja e executa a assistência de enfermagem obstétrica no pré-natal por meio de anamese, preparo da gestante para exame, consulta de enfermagem e encaminhamento para dinamizar o atendimento do serviço e possibilitar controle adequado da gestante;

2. planeja e executa a assistência de enfermagem obstétrica no trabalho de parto por meio do diagnóstico, da admissão da parturiente, da observação e controle do pré-parto, do preparo e assistência aos partos normais com ou sem episiotomia e dos cuidados imediatos ao recém-nascido para dar conforto e segurança à parturiente, detectar intercorrências e prevenir traumas e sequelas de parto;

3. planeja e executa a assistência de enfermagem no puerpério por meio da verificação dos sinais vitais, das perdas genitais, do controle da involução uterina e da lactação para prevenir hemorragias, infecções puerperais, mastites $\mathrm{e}$ orientar a amamentação natural;

4. orienta gestantes, parturientes e puérperas por meio de entrevistas, palestras e cursos de preparação para o parto e de puericultura neo-natal para a proteção da saúde, principalmente, da mãe e do filho.

\section{AUDITOR EM ENFERMAGEM}

Executa tarefa similares às do enfermeiro, em geral (E-0297) e exerce atividades de assessoramento técnico e administrativo em órgãos ou instituiçōes por meio de estudos, análises, avaliaçōes, levantamentos, orientaçōes e outros a fim de participar de programas globais de saúde:

1. desenvolve os serviços de enfermagem, traçando as diretrizes gerais do programa de trabalho em consonância com os objetivos filosófico-políticos da instituição e a fim de realizar as metas programadas por ela; 
OGUIsso, T. e SCHMmT, M.J. - A Propósito da Classificação Brąileira Uniforme de Ocupaçóes. Rev. Bras. Enf.; DF, 29 : 6-23, 1976

2. participa no planejamento, desenvolvimento e avaliação de projetos e pesquisas por meio de estudos, levantamentos e comunicação com outros órgãos a fim de que sejam estabelecidos programas e metas prioritárias de saúde;

3. interpreta as necessidades de enfermagem, analisando relatórios, promovendo e acompanhando levantamentos de recursos e necessidades nas áreas de atuação, e prepara informes, documentos e arrazoados a fim de assessorar autoridades superiores nos assuntos de enfermagem;

4. participa de grupos de trabalho comissões e equipes multiprofissionais, emitindo pareceres de sua especialidade e executando trabalhos específicos visando analisar problemas, estudar soluções e propor medidas corretivas;

5. estuda e prepara normas de serviço, regulamentos, roteiros e ordens de serviço a serem aplicados nos órgãos executivos, por meio da análise de relatórios, boletins estatísticos e outros documentos, orientando-os e assessorando-os nessa implantação, a fim de padronizar a assistência de enfermagem em níveis desejáveis;

6. supervisiona os órgãos executivos por meio de visitas periódicas visando orientar a correção de distorções e sugerir adaptações às peculiaridades locais;

7. avalia o nível de assistência de enfermagem prestada nos órgãos executivos por meio de entrevistas com as chefias, análise de relatórios e visitas de supervisão a fim de propor programas de treinamento específico para racionalização e atualização das técnicas;

8. propõe remanejamento de pessoal, material e equipamentos ou reaproveitamento de instalações por meio da análise de dados estatísticos, relatórios e visita aos órgãos locais para sugerir a melhor utillização das disponibilidades;

9. promove e coordena reunióes e encontros periódicos com as chefias dos ór- gãos executivos, levantando problemas, estabelecendo prioridades, sugerindo soluções e designando comissōes especials para estudo de problemas regionais ou locais visando melhor aproveitamento dos recursos;

10. organiza e mantém um registro de informações sobre os órgãos executivos e o pessoal de enfermagem por meio de anotação de ocorrências em fichas próprias para fins de consulta, avaliação e documentação;

11. analisa pedidos, consultas, problemas e outras indagações de ordem técnico-administrativa, fundamentando-se em estudos, levantamentos, relatórios, resultados de pesquisas operacionais, fichas de ocorrências e outros documentos a fim de proferir despachos em processos e servir de subsídio para elaboração de outros documentos e pareceres;

12. colabora com instituições de ensino de enfermagem e com outras da área de saúde, proporcionando-lhes facilidades na realização de estágios, visitas e pesquisas com o propósito de promover o aprendizado ou $\mathrm{o}$ aperfeiçoamento de técnicas e processos;

13. prepara relatório periódico das atividades desenvolvidas, registrando fatos e ocorrências mais importantes para fins de documentação e conhecimento das autoridades superiores.

\section{ENFERMEIRO PUERICULTOR E PEDIATRICO}

Executa tarefas similares às do enfermeiro, em geral (E-0297) e presta assistência de enfermagem à criança sadia ou enferma por meio da observação, identificação das necessidades, orientação de familiares e/ou responsáveis, supervisão e/ou administração de medicamentos, tratamentos e alimentação a fím de poder acompanhar o seu desenvolvimento bio-psico-social: 
OGuIsso, T. e SCHMmT, M.J. - A Propósito aa Classificação Brasileira Uniforme de Ocupaçōes. Rev. Bras. Enf.; DF, 29 : 6-23, 1976.

1. avalia o estágio de crescimento e desenvolvimento da criança, por comparação com os padrōes normais de crescimento, a fim de proporcionar-lhe os meios para que cresça e adquira as habilidades e as atitudes de um grau mais avançado de desenvolvimento;

2. proporciona à criança os meios de desenvolvimento dando carinho, alimento, recreação, proteção física, estímulos senso-motores da linguagem, das atividades mentais e sociais e da disciplina, para ajudá-la a alcançar um grau mais avançado de crescimento e desenvolvimento;

3. avalia as possibilidades de maturidade ou imaturidade emocional, de linguagem e de raciocínio da criança para perceber, entender e reagir nas experiências novas e difíceis por meio da observação sistematizada e do apoio com o fím de ajudá-la para que em menos tempo enfrente a realidade com menor sofrimento;

4. coopera no plano médico terapêutico e profilático, administrando e/ou controlando a medicação, tratamento e a alimentação das crianças em estado grave para a solução de carências alimentares, anorexias, desidrataçōes, infecçōes, parasitoses e prevenção de tuberculose, tétano, difteria, coqueluche, sarampo, poliomielite, varíola, rubéola, parotidite e outras doenças;

5. auxilia os familiares no reconhecimento das necessidades da criança por meio de entrevistas de orientação para a manutenção ou recuperação de sua saúde.

\section{ENFERMEIRO PSIQUIATRICO}

Executa tarefas similares às do enfermetro, em geral (E-0297) e colabora no płanom édico profilático e terapêutico de doenças mentais, prestando assistência específica para favorecer o ajustamento do indivíduo à comunidade preparando esta para receber o egresso:

1. colabora na seleção do pessoal, por meio de entrevista e observação do comportamento no trabalho, para favorecer o relacionamento pessoal de enfermagempaciente;

2. admite 0 paciente na unidade, procurando auxiliá-lo na aceitação da terapêutica e do regulamento da instituição, prestando cuidados especiais nos casos de excitação psico-motora para possibilitar o tratamento apropriado;

3. introduz o doente mental apresentando-o e ajudando-o na integração ao grupo terapêutico comunitário, para obter sua cooperação no tratamento programado;

4. coleta dados de observação do comportamento do paciente nas 24 horas por meio do relatório de enfermagem, passagem de plantão, plano de cuidados de enfermagem e presta informes ao psiquiatra e aos demais membros da equipe de saúde mental para subsídio diagnóstico, conduta terapêutica, principalmente, praxiterapia;

5. orienta familiares do paciente por meio de entrevistas e esclarecimentos sobre a doença e o comportamento adequado da família em relação ao mesmo para reduzir os problemas pertinentes à permanência do egresso no lar, no trabalho e na comunidade.

\section{ENFERMEIRO DE CENTRO CIRÚRGICO}

Executa tarefas similares às do enfermeiro em geral e administra o centro cirúrgico, programando, coordenando e supervisionando o atendimento da dinâni:ca nas salas de operações, de recuperação pós-anestésica e centro de material esterilizado, a fim de assegurar a eficiência do serviço: 
OGUISso, T. e SCHMIDT, M.J. - A Propósito da Classificação Brasileira Uniforme de Ocupaçōes. Rev. Bras. En?.; DF, 29 : 6-23, 1976.

1. programa e coordena a realização de cirurgias prevendo e provendo material, equipamentos e medicamentos para a equipe cirúrgica a fim de proporcionar maior segurança e eficiência no seu desenvolvimento;

2. supervisiona a montagem das salas de operaçōes verificando a ordem e a disposição do material, providenciando o atendimento de pedidos especiais para assegurar o transcurso normal da cirurgia;

3. recebe e identifica o paciente na sala de cirurgia verificando se lhe foram prestados os cuidados pré-operatórios e assiste-o proporcionando-lhe apoio, conforto e segurança para diminuir as tensōes e traumas;

4. verifica as anotaçōes de cirurgia, examinando prontuários e impressos próprios do Centro Cirúrgico, a fim de orientar o pós-operatório e observar a discriminação do material e medicamentos utilizados;

5. providencia 0 acondicionamento adequado das peças e a sua remessa para exame anátomo-patológico, observando as técnicas de conservação e encaminhando-as ao laboratório de acordo com a rotina a fim de evitar extravios e deterioração;

6. elabora, supervisiona e executa c plano de cuidados de enfermagem para os pacientes na sala de recuperação pósanestésica, por meio do controle dos sinais vitais, da hemorragia, das drenagens a fim de prevenir acidentes e intercorrências no pós-operatório imediato;

7. mantém os equipamentos e aparelhos em condições de uso imediato, verificando periodicamente o funcionamento e providenciando o conserto dos mesmos, quando necessário, para o atendimento das emergências;
8. prepara o equipamento especializado, revendo o seu funcionamento e providenciando sua substituição ou conserto, quando necessário, para garantir a realização da cirurgia;

9. verifica o preparo, a esterilização e a guarda do instrumental, de luvas, fios, campos, aventais, compressas, gases, seringas, agulhas, drenos e outros, observando as técnicas utilizadas, testando os aparelhos de esterilização para assegurar a assepsia cirúrgica.

\section{ENFERMEIRO DE TERAPIA INTENSIVA}

Executa tarefas similares à do enfermeiro, em geral (E-0297) e presta assistência direta de enfermagem a pacientes graves e recuperáveis por meio da observação e controle de monitores, respiradores artificiais, aspiradores contínuos ou intermitentes e outros, para porporcionar o maior grau possível de bem-estar físico, mental e social:

1. identifica as necessidades básicas do paciente pela observação sistematizada, pela análise do prontuário e entrevista com familiares e elabora plano escrito dos cuidados de enfermagem para assegurar a continuidade do tratamento nas 24 horas;

2. presta assistência direta de enfermagem instalando e controlando aparelhos especiais, como monitores, respiradores artificiais, aspiradores contínuos ou intermitentes, e outros a fim de evitar manipulação excessiva do paciente grave, facilitar o controle de sinais vitais, possibilitar a função respiratória, evitar o acúmulo de secreçōes e garantir a eficiência dos procedimentos;

3. ministra alimentos aos pacientes impossibilitados por meio de sondagem ou gavage para evitar aspiração ou traumatismo do tracto digestivo superior. 
OGUISso, T. e SCHMIDT, M.J. - A Propósito da Classificação Brasileira Uniforme de Ocupaçōes. Rev. Bras. Enf.; DF, 29 : 6-23, 1976.

\section{DESCRIÇAXO DAS TAREFAS} PRINCIPAIS E OPCIONAIS

\section{PROFESSOR DE CURSO SUPERIOR DE ENFERMAGEM E OBSTETRICIA}

Código 1-31.75

Ministra cursos de graduação e pósgraduação em enfermagem e obstetrícia exercendo atividades didáticas, de pesquisa e de assessoramento, para formação e aperfeiçoamento de enfermeiros:

1. elabora o plano de ensino das disciplinas que ministra, discriminando objetivos, programa, carga horária do ensino teórico e prático e da experiência de campo, métodos didáticos utilizados, atividades discentes, critérios de avaliação do aprendizado e bibliografia básica, a fim de assegurar a eficiência do ensino;

2. elabora o plano de ensino teórico e prático, discriminando objetivos, esquema de aula, método didático utilizado, atividades discentes, avaliação do aprendizado e bibliografia específica e atualizada e preparando o material auxiliar audiovisual, que possibilite ao aluno melhor aproveitamento;

3. executa o plano de ensino, por meio de preleção, seminário, discussão de grupo, painel, simpósio, demonstração e revisão de técnicas específicas visando desenvolver o raciocínio lógico e o aprendizado;

4. prepara e corrige provas, orienta e corrige trabalhos com base no plano da disciplina para avaliar o aprendizado;

5. programa, supervisiona e avalia a prática profissional de campo, em serviços de proteção, recuperação e reabilitação da saúde, selecionando experiências, orientando a execução de planos de cuidados, fazendo demonstração e re- visao das técnicas e acompanhando o desempenho das atividades dos estudantes para ensinar-lhes os princípios científicos fundamentais da assistência de enfermagem;

6. executa atividades de pesquisa, preparando, orientando e/ou executando planos e projetos para melhorar a assistência de enfermagem com a aplicação dos resultados na prática e no ensino;

7. participa de reuniōes técnicas e administrativas, congressos, jornadas, encontros, grupos de trabalho sobre educação e/ou disciplinas afins, discutindo, sugerindo ou apresentando trabalhos, a fim de colaborar e acompanhar o desenvolvimento técnico científico da profissão;

8. prepara material bibliográfico, escrevendo e publicando trabalhos, folhetos e livros para consulta e orientação de estudantes e profissionais da enfermagem;

9. assessora profissionais e entidades de educação e de assistência, sobre preparo de pessoal, estrutura e funcionamento de escolas, serviços de saúde em geral e de enfermagem em particular, emitindo pareceres, preparando informes ou documentos para orientação e elucidação em assuntos específicos;

Pode dirigir escolas ou faculdades de enfermagem, de técnicos e de auxiliares de enfermagem;

Pode desempenhar tarefas similares às do enfermeiro, em geral (E-0297).

PROFESSOR DE ENFERMAGEM - de $1 .^{\circ}$ e $2 .^{\circ}$ graus

Código 1-32.75

Ministra cursos e disciplinas de enfermagem ou correlatas em estabelecimen- 
OGUISSO, T. e SCEMMT, M.J. - A Propósito da Classificaçảo Brasileira Uniforme de Ocupaçōes. Rev. Bras. Enf.; DF, $29: 6-23,1976$.

tos de ensino de $10^{\circ}$ e $2 .^{\circ}$ grau, exercendo atividades administrativas, didáticas e de pesquisa, para a formação de auxiliares e técnicos de enfermagem;

1. ensina em escolas de técnico e de auxiliares de enfermagem, elaborando $o$ plano das disciplinas e das aulas, definindo os objetivos, programa, carga horária, método didático e critérios para avaliação do estudante e o plano de prática profissional para possibilitar ao aluno melhor aproveitamento e atender dispositivos legais;

2. desenvolve o plano de aula por preleção, orientação ou coordenação de seminários, discussão de grupos ou demonstração e revisão de técnicas de cuidados de enfermagem, para motivar o aprendizado;

3. prepara, aplica e corrige provas, orienta e corrige trabalhos com base no pla- no da disciplina para avaliação dos métodos de ensino e nível de aproveitamento;

4. supervisiona e avalia a prática profissional nos campos de estágio em hospitais e ambulatórios, fazendo demonstração e revisão das técnicas de enfermagem e acompanhando o desempenho das atividades dos estudantes na prestação de cuidados de enfermagem aos pacientes sob sua responsabilidade para assegurar a eficiência do aprendizado.

Pode dirigir escolas ou coordenar cursos de enfermagem de $1 .^{\circ}$ e $2 .^{\circ}$ grau;

Pode ministrar ensino de disciplinas correlatas com a enfermagem em escolas de $1 .^{\circ}$ e $2 .^{\circ}$ grau em geral, como biologia, higiene, puericultura e outras;

Pode desempenhar tarefas similares às do enfermeiro, em geral (E-0297). 